\title{
A BUSCA PELA LEGITIMIDADE DA RELAÇÃO POLIAMOROSA COM BASE EM PRINCÍPIOS CONSTITUCIONAIS E A DISCUSSÃO SOBRE A VALIDADE DAS ESCRITURAS PÚBLICAS QUE AS DECLARAM ${ }^{1}$
}

THE SEARCH FOR THE LEGITIMACY OF POLYAMOROUS RELATIONSHIP BASED ON CONSTITUTIONAL PRINCIPLES AND THE DISCUSSION ON THE VALIDITY OF PUBLIC SCRIPTURES THAT DECLARE THEM

Bruna Terra Teodoro da SILVA ${ }^{2}$

Marcelo TOFFANO ${ }^{3}$

ISSUE DOI: $10.21207 / 2675-0104.2018 .761$

\section{RESUMO}

Com a promulgação da Carta Magna, houve a constitucionalização do Direito Privado. A partir desse marco, as normas do Direito de Família passaram a ser interpretadas a luz dos princípios

\footnotetext{
${ }^{1} \mathrm{O}$ presente artigo sintetiza a monografia de conclusão da pesquisa, realizada para o Programa Interno de Bolsas de Iniciação Científica (PIBIC 2017-2018) da Faculdade de Direito de Franca (FDF), Franca/SP.

${ }^{2}$ Discente da Faculdade de Direito de Franca (FDF), Franca/SP. Bolsista do Programa Interno de Bolsas de Iniciação Científica (PIBIC 2017-2018).

${ }^{3}$ Doutor em Direito (Área de Concentração: Função Social no Direito Constitucional) pela Faculdade Autônoma de Direito - FADISP (2014-2018). Mestredo em Direito (Área de Concentração: Direito das Relações Econômico-empresariais) pela Universidade de Franca (2006). Graduado em Direito pela Universidade de Franca (2001). Especialista em Direito Civil pela Universidade de Franca (2003). Atualmente é professor titular da Faculdade de Direito de Franca e orientador de pesquisas científicas. Atua como advogado desde 2002.
} 
constitucionais, fomentando o alargamento do conceito de família, que passou a ser associada como instrumento de realização pessoal; Tanto é citou exemplificativamente novos arranjos familiares, quais sejam, a família monoparentel e a união estável.Com o reconhecimento da família homoafetiva pelo STF na ADPF132 e ADI 4277, constatou-se que o artigo 226 da C.F. tratava-se realmente de norma inclusiva, isto é, o Estado está incumbido de proteger qualquer entidade familiar que tenha como base o afeto. Por conseguinte, a família poliamorosa é legal e digna de tutela jurisdicional.

Palavras-chaves: Constitucionalização. Princípios. Poliamor. Jurisprudência. Escrituras.

ABSTRACT

With the promulgation of the Magna Carta, there was the constitutionalization of Private Law. From this milestone, the norms of Family Law began to be interpreted in the light of constitutional principles, fostering the extension of the concept of family, which became associated as an instrument of personal fulfillment; So much, he cited exemplary new family arrangements, that is, the single-parent family and the stable union. With the recognition of the homoaffective family by the STF in ADPF132 and ADI 4277, it was verified that article 226 of the CF was indeed an inclusive norm, that is, the state is charged with protecting any family entity based on affection. Therefore, the polyamorous family is legal and worthy of judicial protection.

Keywords: Constitutionalisation. Principles. Polyamory. Jurisprudence. Scriptures.

\section{$1 \quad$ INTRODUÇÃO}

O projeto de iniciação elaborado possui a finalidade de solidificar o entendimento de que o tempo e o espaço influenciam diretamente no conceito de família. Em tal caso, a complexidade das transformações sociais, principalmente referente à relações pessoais, nos faz afirmar que a Constituição Federal de 1988, fixou um rol meramente taxativo de entidades familiares no artigo 226, diferentemente do Código Civil de 1916, que reconhecia o casamento civil como o único responsável por instituir a família.

Isto posto, a união poliamorosa seria tão reconhecida como as outras, com a característica de não ferir a fidelidade conjugal e de seus membros buscarem a sua realização no campo sentimental.

Esta tese será ratificando com a explanação de quatro princípios constitucionais, são eles: o da dignidade da pessoa humana(basilar), liberdade, igualdade e afetividade.

Outrossim, será mencionado o julgamento do Supremo Tribunal Federal na Ação Direta de Inconstitucionalidade n. ${ }^{\circ} 4.277$ e a Arguição de Descumprimento de Preceito Fundamental n. ${ }^{\circ} 132$, que reconheceu a união poliafetiva como entidade familiar por meio do instituto da união estável. 
Ainda, será abordada e apresentada diversas decisões recentes de nossos tribunais que reconheceram a união poliafetiva como entidade familiar, sendo fundamentadas pelo processo de constitucionalização do Código Civil e pelos princípios da Constituição Federal.

Por fim, será exposto a discussão das validades das escrituras públicas que as declaram, com enfoque na recente decisão do $\mathrm{CNJ}$ as proibiram de serem lavradas, com o fundamento de não terem respaldo no ordenamento jurídico e nem na jurisprudência do Supremo Tribunal Federal (STF).

\section{BREVE ANÁLISE DA EVOLUÇÃO DO CONCEITO DE FAMÍLIA}

Friedrich Engels em seu livro "A origem da família, da propriedade privada e do Estado " " descreveu a evolução do conceito de família, pontuando que existia um estado primitivo de promiscuidade e que a partir desse estado formaram-se as famílias consanguíneas, posteriormente as punaluanas, subsequentemente as sindiásmicas e, por fim, as monogâmicas.

Os membros da família consanguínea se relacionavam uns com outros indistintamente, sem que houvesse qualquer impedimento pelo grau de parentesco.

Já os integrantes da família punaluana, em uma primeira etapa, não eram mais simultaneamente pais e filhos; e ulterinamente, na segunda etapa, não eram mais irmãos, começando pela exclusão dos irmãos uterinos e acabando pela proibição do matrimônio até entre os irmãos colaterais.

A família sindiásmica foi marcada por uniões entre um homem e uma mulher, sendo que a poligamia e a infidelidade eram direitos dos companheiros, embora a mulher exercesse papel central dentro do seu núcleo familiar.

Devido ao desenvolvimento das atividades agrícolas e a criação de animais, houve o acúmulo de riquezas e o surgimento da propriedade privacidade, fazendo que o homem passasse a ter um papel de

\footnotetext{
${ }^{4}$ ENGELS, Friedrich. A Origem da família, da propriedade privada e do Estado. Rio de Janeiro: Civilização Brasileira, 1984. p. 134.
} 
superioridade em relação às companheiras e os filhos passassem a serem gerados com o intuito de se tornarem força de trabalho e para que herdassem a acumulada pelas atividades econômicas de seus descendentes. $\mathrm{O}$ que revela que o conceito de família estava intimamente relacionado a produção patrimonial e sua conservação.

Foi diante deste contexto que a família monogâmica surgia. Interessante que nesta fase, o casamento civil passou a ser único bem jurídico tutelado pela norma, isto é, somente conferira o status de família àqueles agrupamentos originados pelo casamento no civil.

O Código Civil de 1916 retratou esse contexto fático ainda do século XVIII. Desta maneira, a imposição legal já nasceu pretérita.

Contudo, com o advento da Constituição de 1988, o Direito Civil sofreu o processo de constitucionalização, isto é, todas as suas normas começaram a ser interpretadas pelos ditames constitucionais.

Nesse diapasão aponta Marcela Rodrigues Figueiredo e Fabiana Alves Mascarenhas (2012, p.17): "O movimento de constitucionalização do direito civil permitiu uma releitura de todo ordenamento a partir de uma interpretação axiológica da constituição, tendo como norte hermenêutico basilar o princípio da dignidade da pessoa humana.5"

Por conseguinte, a definição de família sofreu grandes transformações, passando a ser associada como uma instituição em que os membros passaram a buscar sua realização pessoal, ou seja, não perdeu o viés patrimonial e procracional. Paulo Lobo (2011, p.27) resume tal entendimento ao dizer que:

\begin{abstract}
A família tradicional, que até então, se caracterizava pelo viés patrimonial e pela multiplicidade de laços individuais passa a fundar-se na solidariedade, na cooperação, no respeito à dignidade de cada um de seus membros, que se comprometem mutualmente em uma comunidade de vida. A família constitucional pós-1988 é compreendida como o espaço de realização pessoal afetiva, onde o interesse patrimonial não é mais o objetivo principal de sua instituição. Sendo que, a repersonalização de suas relações revitaliza as unidades familiares, em seus mais variados tipos ou arranjos. $^{6}$
\end{abstract}

Importante ressaltar que além da Constituição Federal ter vinculado a interpretação do conceito de família aos princípios regras da

\footnotetext{
${ }^{5}$ FIGUEIREDO, M. R. S.; MASCARENHAS, F. A. A Abertura do Conceito de Família No Direito Brasileiro: para além do rol do art. 226 da Constituição Federal de 1988. In: José Sebastião de Oliveira, Mariana Ribeiro Santiago. (Org.). Direito de família. Florianópolis: FUNJAB, 2012, p. 17. Disponível em: http://www.publicadireito.com.br/artigos/?cod=0ebb145bdffd37c6. Acesso em: 23 jul. 2018.

${ }^{6}$ LÔBO, Paulo Luiz Netto. Direito Civil: Famílias. 4. ed. São Paulo: Saraiva, 2011. p. 27.
} 
dignidade da pessoa humana, da liberdade, da igualdade e da afetividade, como visto, trouxe em seu preceito novos modelos exemplificativos de entidade familiar, dentre eles a união estável e a família monoparental.

Desta maneira, o casamento civil passou a ser uma das formas instituir um núcleo familiar, sendo o dever do Estado assegurar a proteção de todos eles. Maria Berenice Dias (2015, p. 36) dispõe que:

Procedeu o legislador constituinte ao alargamento do conceito de família e emprestou juridicidade ao relacionamento fora do casamento. Afastou da ideia de família o pressuposto do casamento, identificando como família também a união estável entre um homem e uma mulher. A família à margem do casamento passou a merecer tutela constitucional porque apresenta condições de sentimento, estabilidade e responsabilidade necessários ao desempenho das funções reconhecidamente familiares. Nesse redimensionamento, passaram a integrar o conceito de entidade familiar as relações monoparentais: um pai com os seus filhos. Agora, para a configuração da família, deixou de se exigir necessariamente a existência de um par, o que, consequentemente, subtraiu de seu conceito a finalidade procriativa.

Com o julgamento da ADIN 4277 e da ADPF 132, em que o Supremo Tribunal Federal reconheceu as uniões homoafetivas como entidades familiares por meio do instituto da união estável, acarretou ainda mais o alargamento do conceito de família, nos fazendo afirmar que o rol contido no artigo 226 da Constituição Federal é meramente exemplificativo.

Como bem aponta Farias e Rosenvald (2013, p. 84) ao dizer que: "o conceito trazido no caput do artigo 226 é plural e indeterminado, firmando uma verdadeira cláusula geral de inclusão". 7

Desprende-se desse raciocínio que qualquer entidade familiar, ainda que não expressa no texto constitucional, seja digna de proteção estatal. Vejamos: "[...] é preciso ressaltar que o rol da previsão constitucional não é taxativo, estando protegida toda e qualquer entidade familiar, fundada no afeto, esteja, ou não, contemplada expressamente na dicção legal ${ }^{8}$ ".

Isto posto, sendo o conceito de família aberto, elástico e vinculado ao afeto e aos princípios constitucionais, não há justificativa

\footnotetext{
${ }^{7}$ FARIAS, Cristiano Chaves de. A Separação Judicial à Luz do Garantismo Constitucional: A afirmação da dignidade humana como um réquiem para a culpa na dissolução do casamento, 2006. p.667.

${ }^{8}$ FARIAS, Cristiano Chaves de. A Separação Judicial à Luz do Garantismo Constitucional: A afirmação da dignidade humana como um réquiem para a culpa na dissolução do casamento, 2006. p.66.
} 
normativa que impeça o reconhecimento da família poliamorosa e o seu livre exercício.

Este entendimento será ratificado ao analisarmos o espírito de quatro princípios constitucionais: dignidade da pessoa humana, liberdade, igualdade e afetividade.

\section{PRINCÍPIOS CONSTITUCIONAIS}

\subsection{DIGNIDADE DA PESSOA HUMANA}

Com embasamento doutrinário reconheceremos que a Dignidade da Pessoa Humana apesar de ser um conceito aberto, plástico e plural, como Luís Roberto Barroso define, estará sempre associado a liberdade do homem em fazer suas próprias escolhas e buscar sua própria felicidade. $\mathrm{E}$ mais, ao respeito que cada ser humano deve ter com o outro diante de suas posições afetivas, morais e sociais. Nesse sentido temos a definição de Ingo Wolfgang Sarlet (2001, p. 60):

A dignidade da pessoa humana corresponde à qualidade intrínseca e distintiva de cada ser humano que o faz merecedor do mesmo respeito e consideração por parte do Estado e da comunidade, implicando, neste sentido, um complexo de direitos e deveres fundamentais que assegurem a pessoa tanto contra todo e qualquer ato de cunho degradante e desumano, como venham a lhe garantir as condições existenciais mínimas para uma vida saudável, além de propiciar e promover a sua participação ativa e co-responsável nos destinos da própria existência e da vida em comunhão com os demais seres humanos, independente. ${ }^{9}$

Posto isso, constatamos o quão importante e necessário dentro do nosso ordenamento jurídico e principalmente para resguardar a constitucionalidade da Relação Poliamorosa, já que opção de adotar esse novo conceito de família está intimamente ligado a capacidade do ser humano de direcionar o rumo de sua própria vida segundo sua consciência. Além do mais, a Dignidade Humana elevada à condição de princípio, faz com que o intérprete, dentro das possibilidades jurídicas e

\footnotetext{
${ }^{9}$ SARLET, Ingo Wolfgang. A eficácia dos direitos fundamentais. 2. ed. Porto Alegre: Livraria do Advogado, 2001. p. 61.
} 
reais existentes, a considere como ponto de partida para a interpretação dos demais dispositivos.

Nessa acepção Flávia Piovesan (2000, p.54) nos ensina que:

A dignidade da pessoa humana formalizada enquanto princípio, encontra-se como princípio matriz da Magna Carta, servindo-se de elemento orientador da interpretação das normas edificadoras dos direitos e garantias fundamentais, provocando nesse sentido, a análise da exigência ética no atuar jurisdicional em todo a sistemática jurídica brasileira. ${ }^{10}$

Sendo assim, ao aplicarmos o Princípio da Dignidade da Pessoa Humana no artigo $226, \S 3^{\circ}$ da Constituição Federal, podemos sustentar uma interpretação extensiva do instituto da união estável aos moldes esperado pela sociedade contemporânea, o que consequentemente incorporaria nesse instituto a Relação Poliamorosa. Para ratificar esse entendimento encerraremos com a lição de Maria Berenice Dias (2010, p.63), que diz que:

O princípio da dignidade humana significa, em última análise, uma igual dignidade para todas as entidades familiares. Assim, é indigno dar tratamento diferenciado às várias formas de filiação ou aos vários tipos de constituição de família com o que se consegue visualizar a dimensão do espectro desse princípio que tem contornos cada vez mais amplos. ${ }^{11}$

Posto isto, em nome do princípio constitucional da dignidade da pessoa humana, a família poliamorosa deve ser reconhecida como entidade familiar.

\subsection{PRINCÍPIO DA IGUALDADE}

O Princípio da Igualdade deve ser entendido como aquele que veda que a lei crie prerrogativas arbitrárias somente a uma parcela da sociedade de modo a gerar desigualdades. Destarte, não é vedado que a lei trate igualmente os iguais e desigualmente os desiguais na medida em que se desigualam. Nos dizeres de Manoel Gonçalves Ferreira Filho (1990, p. 243):

${ }^{10}$ PIEOVESAN, Flávia. Direitos Humanos e o Direito Constitucional Internacional. 4.ed. São Paulo: Max Limonad, 2000. p. 54.

${ }^{11}$ DIAS, Maria Berenice. Manual de direito das famílias. 10. ed. São Paulo: Revista dos Tribunais, 2015. p. 62 
O princípio da igualdade não proíbe de modo absoluto as diferenciações de tratamento. Vedam apenas aquelas diferenciações arbitrárias, as discriminações. Na verdade, o tratamento desigual dos casos desiguais, na medida em que se desigualam, é exigência do próprio conceito de Justiça. $^{12}$

Nesta linha de raciocínio Fernanda Duarte Lopes Lucas da Silva (2003, p. 91) preleciona que:

[...] o princípio da igualdade jurídica determina que a lei não pode ser fonte de privilégio ou de perseguições, mas sim instrumento regulatório da vida social, que necessita tratar equitativamente todos os cidadãos. Ao se cumprir a lei, todos os seus destinatários hão de receber tratamento parificado, de modo que ao próprio ditame legal é defeso instituir disciplinas diversas para situações equivalentes. Essa exigência, por sua vez, não interdita a possibilidade de tratamento diferenciado, que se razoável, tem abrigo na ordem constitucional. ${ }^{13}$

Ainda, o Princípio da Igualdade se desdobra em estabelecer que é dever do juiz sanar as omissões dos legisladores, isto é, garantir direitos a quem a lei não confere. É assim que pensa Maria Berenice Dias (2015, p. 48):

\begin{abstract}
Assim como a lei não pode conter normas que arbitrariamente estabeleçam privilégios, o juiz não deve aplicar a lei de modo a gerar desigualdades. Em nome do princípio da igualdade, é necessário que assegure direitos a quem a lei ignora. Preconceitos e posturas discriminatórias, que tornam silenciosos os legisladores, não podem levar também o juiz a se calar. Imperioso que, em nome da isonomia, atribua direitos às situações merecedoras de tutela. ${ }^{14}$
\end{abstract}

Desta maneira, pelo fato da união poliafetiva não ser provida de tutela jurisdicional, o magistrado ao se deparar com essa situação fática deve garantir todos os direitos inerente às outras entidades familiares constituídas por meio da união estável. O que pode ser extraído do ensinamento Rafael da Silva Santiago (2014, p. 152):

[...]por se tratar de uma legítima família desprotegida - dada a ausência de tutela normativa - e alvo de constantes discriminações, o Estado deve propiciar condições para que esse desequilíbrio seja

\footnotetext{
${ }^{12}$ FERREIRA FILHO, Manoel Gonçalves. Curso de Direito Constitucional - De acordo com a Constituição de 1988, p. 242-43.

${ }^{13}$ Ibidem.

${ }^{14}$ DIAS, Maria Berenice. Manual de direito das famílias. 10. ed. São Paulo: Revista dos Tribunais, 2015. p. 48.
} 
compensado com o exercício de direitos capazes de tutelar ainda mais esse novo arranjo familiar. ${ }^{15}$

Assim, pelo fato do Princípio da Igualdade vedar tratamento heterogêneo aleatoriamente e conceder ao juiz a prerrogativa de assegurar direitos a quem a lei não confere, infere-se a legitimidade da relação poliamorosa em nosso ordenamento jurídico.

\subsection{PRINCÍPIO DA LIBERDADE}

O princípio da liberdade diz respeito, no ramo do Direito de Família, na liberdade que o indivíduo desfruta de constituir, desconstituir e reinventar a entidade familiar, isto é, diz respeito a sua liberdade de escolha. Pode-se dizer que o princípio está vinculado ao princípio da autonomia privada. É o que nos ensina Paulo Lôbo (2012, p.70):

$\mathrm{O}$ princípio da liberdade diz respeito não apenas à criação, manutenção ou extinção dos arranjos familiares, mas à sua permanente constituição e reinvenção. Tendo a família se desligado de suas funções tradicionais, não faz sentido que ao Estado interesse regular deveres que restringem profundamente a liberdade, a intimidade e a vida privada das pessoas, quando não repercutem no interesse geral. ${ }^{16}$

Isto posto, não cabe ao Estado interferir na esfera privado dos indivíduos quando os mesmos não estão causando prejuízo contra terceiro. Assim sendo, não concerne ao Estado vedar que os membros das uniões poliafetivas tenham os mesmos direitos e deveres das outras uniões pautadas no instituto da união estável.

\subsection{PRINCÍPIO DA AFETIVIDADE}

O princípio da afetividade, implícito no corpo da Constituição Federal, apesar de ser um conceito aberto, sustenta a ideia de que é a

\footnotetext{
${ }^{15}$ SANTIAGO, Rafael da Silva. O mito da monogamia à luz do Direito Civil-constitucional: A necessidade de uma proteção normativa às relações de poliamor. 2014. 258 f. Dissertação (Mestrado em Direito). Brasília. Programa de Pós-Graduação em Direito, Universidade de Brasília, 2014. p. 152. ${ }^{16}$ LÔBO, Paulo Luiz Netto. Direito Civil: Famílias. 4.ed. 2. São Paulo: Saraiva, 2012, p. 73.
} 
presença do afeto nas relações interpessoais que determinara a existência da entidade familiar:

Como todo princípio, ostenta fraca densidade semântica, que se determina pela mediação concretizadora do intérprete, ante cada situação real. Pode ser assim traduzido: onde houver uma relação ou comunidade unidas por laços de afetividade, sendo estes suas causas originárias e final, haverá família (LOBO, 2002). ${ }^{17}$

Pode dizer então que a partir da Constituição de 1988 “(...) a concepção da família formada por laços afetivos de carinho, de amor" (DIAS, 2013, p.28). ${ }^{18}$

Como disserta Calderón (2013, p. 239):

O texto de 1988 não deixava dúvidas de que tratava de um novo modelo de família, totalmente diverso do que era tutelado pela codificação civil anterior, com preponderância do afeto, do respeito, da liberdade, da igualdade, da dignidade, da solidariedade e da cooperação. ${ }^{19}$

Em suma, absorve-se do Princípio da Afetividade, que o afeto é o elemento que define entidade familiar e ele pode ser direcionado apenas um membro ou quantos bastem.

\section{POLIAMOR NA JURISPRUDÊNCIA BRASILEIRA}

O judiciário brasileiro já alguns anos vem sendo submetido à apreciação de demandas que abordam o reconhecimento da família plúrima. Apesar de ser ainda decisões escassas, os juízes e os tribunais estão reconhecendo a existência de uma entidade familiar, organizada e constituída paralelamente a outra com base nos princípios apontados anteriormente. Senão Vejamos:

APELAÇÃO CÍVEL. ACÃO DE DISSOLUÇÃO DE SOCIEDADE DE FATA C/C PARTILHA DE BENS. UNIÃO ESTÁVEL PARALELA. POSSIBILIDADE.SUJEIÇÃO AO REGIME DE COMUNHÃO PARCIAL DE BENS.

\footnotetext{
${ }^{17}$ LÔBO, Paulo Luiz Netto. Direito Civil: Famílias. 4.ed. 2. São Paulo: Saraiva, 2012, p. 73.

${ }^{18}$ DIAS, Maria Berenice. Manual de direito das famílias. 10. ed. São Paulo: Revista dos Tribunais, 2015. p. 48.

${ }^{19}$ CALDERÓN, Ricardo Lucas. Princípio da afetividade no direito de família. Rio de Janeiro: Renovar, 2013. p. 239.
} 
HONORÁRIOS ADVOCATÍCIOS. EXCESSO. PROVIMENTO PARCIAL. 1. A pluralidade de família consagrada pela Constituição Federal permite que se reconheça uma entidade familiar, organizada e constituída paralelamente a outra que atenda aos mesmos pressupostos. 2. Relação de afeto que reclama conhecimento judicial como forma de respeito ao princípio da dignidade da pessoa humana e ao pluralismo dos núcleos familiares. 3. Não ofende a lei nem a monogamia o reconhecimento de uniões estáveis paralelas que se mantiveram públicas e duradouras por 28 anos consecutivos, com o conhecimento recíproco. Peculiaridades justificada por princípios constitucionais. 4. A Constituição Republicana dispõe, em ser artigo 226: A família, base da sociedade, terá especial proteção do Estado. Nessa previsão constitucional não há eleição de uma família especial para merecer proteção legal, nem poderia, diante da opção pluralista do nosso Estado de Direito e por tratar-se de norma inclusiva, com extensão a todas as formos de família. 5. Sendo uma das hipóteses que excetuam a regra geral de comunicabilidade dos bens, a subrogação deve ser suficientemente provada pela parte a quem interessa, sob pena de não ser reconhecida. 6. A condenação ao pagamento de honorários advocatícios deve ser de acordo com os critérios constantes nas alíneas a,b, c do $\$ 3^{\circ}$ do artigo 20, do CPC. 7. Apelação parcialmente provida. (TJ-MA-APL: 0263562013 MA 0010171-91.2010.8.10.0040, Relator LOURIVAL DE JESUS SEREJO SOUSA, Data de Julgamento: 21/08/2014, $3^{\text {a }}$ Câmara Cível, Data de Publicação:24/09/2014). (grifo nosso)

Em uma decisão mais recente, a jurisprudência sustenta o reconhecimento da união estável simultânea se perfaz quando do preenchimento dos requesitos da união estável:

APELAÇÃO CIVEL. DIREITO DE FAMÍLIA.AÇÃO DE RECONHECIMENTO E DISSOLUÇÃO DE UNIÃO ESTÁVEL POST MORTEM. UNIÃO ESTÁVEL SIMULTANEA. PRINCIPIO DA DIGNIDADE DA PESSOA HUMANA E DA AFETIVIDADE. PROVA ROBUSTA. POSSIBILIDADE. 1. Ainda que de forma incipiente, doutrina e jurisprudência vêm reconhecendo a juridicidade das chamadas famílias paralelas, como aquelas que se formam concomitantemente ao casamento ou à união estável. 2. A força dos fatos surge como situações novas que reclamam acolhida jurídica para não ficarem no limbo da exclusão. Dentre esses casos, estão exatamente as famílias paralelas, que vicejam ao lado das famílias matrimonializadas. 3. Havendo nos autos elementos suficientes ao reconhecimento da existência de união estável entre a apelante e o de cujus, o caso é de procedência do pedido. SENTENÇA MANTIDA. RECURSO IMPROVIDO. (TJ-BA-APL: 0002396-95.2010.8.05.0191, Relator: Maurício Kertzman Szporer, 2a Câmara Cível, Data de Publicação: 15/04/2015). (grifo nosso) 
Isto posto, pela Constituição Federal não prever especial tratamento de uma entidade familiar em detrimento à outra, e sim uma especial proteção à todas as entidades, desprende-se que o artigo 226 tratase de norma inclusiva, não sendo plausível o não reconhecimento pelo judiciário da relação poliamorosa se preenchidos os requisitos da união estável e respeitados os princípios da dignidade da pessoa humana, liberdade, igualdade e afetividade, sob pena de negar a ambas a proteção do direito.

\section{DISCUSSÃO SOBRE A VALIDADE DAS ESCRITURAS PÚBLICAS QUE DECLARAM A RELAÇÃO POLIAMOROSA}

Em 2012, ao ser lavrada uma escritura pública pela tabeliã Cláudia do Nascimento Domingues, na cidade de Tupã, que reconhecia à relação poliamorosa os mesmos efeitos jurídicos da união estável, originou uma grande discussão sobre a validade dessas escrituras.

Diante do ocorrido, a Associação de Direito de Família e das Sucessões (ADFAS) requereu ao Conselho Nacional de Justiça que se posicionasse no sentido de determinar que as Corregedorias - Gerais de Justiça proibissem que os cartórios de seus respectivos estados lavrassem as escrituras públicas para registrar as uniões plúrimas, visto que para a associação reconhecimento do poliamor é ilegal, tendo em vista o disposto na Constituição Federal no artigo 226, parágrafo $3^{\circ}$ e na legislação infraconstitucional, em especial o artigo 1.723 do Código Civil, que reconhece como entidade familiar a união estável entre o homem e a mulher.

Por voto da maioria o Plenário do Conselho Nacional de Justiça (CNJ) decidiu que os cartórios estão proibidos de lavrarem escrituras públicas que declaram a relação poliamorasa. Posicionamento este que representa um retrocesso jurídico, já que a Constituição Federal resguarda proteção estatal indistintamente a todos os arranjos familiares pautados no afeto. 
O estudo da evolução do conceito de família, bem como dos princípios constitucionais conduziu a constatação da legalidade da família poliamorosa dentro do nosso ordenamento jurídico.

Isto posto, assegura a todos aqueles que optam em conviver nesse novo arranjo familiar os mesmos direito e deveres inerentes às outras entidades familiares que são regradas pelo instituto da união estável.

Essa perspectiva apresentada já vem sendo adotada, ainda que de forma escassa, pelo poder judiciário brasileiro, o que representa que estamos caminhando no sentido de reconhecer de uma vez por todas a relação poliamorosa como entidade familiar que produz efeitos jurídicos.

\section{REFERÊNCIAS BIBLIOGRÁFICAS}

BARROSO, Luís Roberto. Curso de direito constitucional contemporâneo: os conceitos fundamentais e a construção do novo modelo. 5. ed. São Paulo: Saraiva,2015.

BRASIL. Supremo Tribunal Federal. ADPF 132, Relator(a): Min. AYRES BRITTO, Tribunal Pleno, julgado em 05/05/2011, DJe-198 DIVULG 13/10/2011 PUBLIC 14/10/2011 EMENT VOL-0260701 PP-00001.

. Tribunal de Justiça do Estado de Pernambuco. $5^{\text {a }}$ Câmara Cível. APL: 2968625. Rel.: José

Fernandes de Lemos. DJ: 28/11/2013. Disponível em: <https://tj-

pe.jusbrasil.com.br/jurisprudencia/158606091/apelacao-apl-2968625-pe>. Acesso em: 26 jul. 2018.

Tribunal de Justiça do Estado do Maranhão. $3^{\text {a }}$ Câmara Cível. APL: 0263562013 MA

0010171-91.2010.8.10.0040, Rel.: Lourival De Jesus Serejo Sousa, Data de Julgamento: 21/08/2014.

Data de Publicação:24/09/2014. Disponível em: < https://tj-

ma.jusbrasil.com.br/jurisprudencia/1 83849278/apelacao-apl-263562013-ma-0010171-

9120108100040/inteiro-teor-183849294> Acesso em: 26 jul. 2018.

Tribunal de Justiça da Bahia. 2a Vara Cível. APL: 0002396-95.2010.8.05.0191. Rel.:

Maurício Kertzman Szporer. Data de Publicação: 15/04/2015. Disponível em: <https://tj-

ba.jusbrasil.com.br/jurisprudencia/363160671/apelacao-ap1 23969520108050191/inteiro-teor-

363160680?ref=juris-tabs TJ-BA-APL: 0002396-95.2010.8.05.0191> Acesso em: 27 de jul. 2018.

Supremo Tribunal Federal. ADI 4277, Relator(a): Min. AYRES BRITTO, Tribunal Pleno, julgado em 05/05/2011, DJe-198 DIVULG 13-10-2011 PUBLIC 14-10-2011EMENT VOL-02607-03 PP-00341 RTJ VOL-00219- PP-00212.

. Tribunal de Justiça do Estado de Pernambuco. $3^{\text {a }}$ Câmara Cível. APL: 7001246 PE 176862 -

7. Rel.: Francisco Eduardo Goncalves Sertorio Canto. DJ 08/03/2012. Disponível em: <http:/tjpe.jusbrasil.com.br/jurisprudencia/21407042/apelacao-apl-7001246-pe-176862-7- tjpe>. Acesso em: 26 jul. 2018. 
CALDERÓN, Ricardo Lucas. Princípio da afetividade no direito de família. Rio de Janeiro: Renovar, 2013.

DIAS, Maria Berenice. Manual de Direito das Famílias. 6. ed. São Paulo: Revista dos Tribunais.

Manual de direito das famílias. 9. Ed. Rev., atual e ampl. De acordo com: Lei 12;344/2010 (regime obrigatório de bens): Lei 12.398/2011 (direito de visita dos avós). São Paulo: Editora RT, 2013.

Eletrônico.

Manual de direito das famílias. 10. ed. São Paulo: Editora Revista dos Tribunais, 2015. Livro

ENGELS, Friedrich. A Origem da família, da propriedade privada e do Estado. Ed. Civilização Brasileira, RJ, 1984.

FACHIN, Luiz Edson. Famílias: entre o Público e o Privado. Problematizando Espacialidades à Luz da Fenomenologia Paralática. In: Revista Brasileira de Direito das Famílias e Sucessões. Porto Alegre: Magister, v. 23, ago./set. 2011. p. 5-14.

FARIAS, Cristiano Chaves de; ROSENVALD, Nelson. Curso de direito civil: direito das famílias. 5. ed. Salvador: Editora JusPODIVM, 2013.

. A Separação Judicial à Luz do Garantismo Constitucional: A afirmação da dignidade humana como um réquiem para a culpa na dissolução do casamento, 2006. p.66.

FIGUEIREDO, M. R. S.; MASCARENHAS, F. A. A Abertura do Conceito de Família No Direito Brasileiro: para além do rol do art. 226 da Constituição Federal de 1988. In: José Sebastião de Oliveira, Mariana Ribeiro Santiago. (Org.). Direito de família. $1^{\circ}$ edição. Florianópolis: FUNJAB, 2012, v.,p.12-32. Disponível em: http://www.publicadireito.com.br/artigos/?cod=0ebb145bdffd37c6. Acesso em: 23 jul. 2018.

GAGLIANO, Pablo Stolze. PAMPLONA FILHO, Rodolfo. Novo Curso de Direito Civil: Direito de Família - as famílias em perspectiva constitucional. V. 6. 5. ed. São Paulo: Saraiva, 2015.

JATOBÁ, Clever. Pluralidade das entidades familiares: os novos contornos da família contemporânea brasileira. Rio de Janeiro: Publit, 2015.

LÔBO, Paulo Luiz Netto. "Entidades familiares constitucionalizadas: para além do numerus clausus". Revista Brasileira de Direito de Família, Porto Alegre: Síntese, n.12, jan./mar.2002.

Direito Civil: Famílias. 4. ed. São Paulo: Saraiva, 2011.

Direito Civil: Famílias. 4.ed. 2. Tiragem. [s.1.]: Saraiva, 2012, p. 70.

MARTINS, F.J.B. Dignidade da pessoa humana. Curitiba: Juruá, 2003.

MONTENEGRO, Manuel Carlos. CNJ. Cartórios são proibidos de fazer escrituras públicas de relações poliafetivas. 26 jun. 2018. Disponível em: < http://www.cnj.jus.br/noticias/cnj/87073- 
cartorios-sao-proibidos-de-fazer-escrituras-publicas-de-relacoes-poliafetivas> Acesso em: 28 jul. 2018.

MELLO, Celso Antônio Bandeira de. O conteúdo Jurídico do Princípio da igualdade. 3. ed. São Paulo: Malheiros Editores, 2014.

PIEOVESAN, Flávia. Direitos Humanos e o Direito Constitucional Internacional. 4.ed. São Paulo: Max Limonad.

SANTIAGO, Rafael da Silva. O mito da monogamia à luz do Direito Civil-constitucional: A necessidade de uma proteção normativa às relações de poliamor. 2014. 258 f. Dissertação (Mestrado em Direito). Brasília. Programa de Pós-Graduação em Direito, Universidade de Brasília, 2014.

SARLET, Ingo Wolfgang. A eficácia dos direitos fundamentais. 2. ed. Porto Alegre: Livraria do Advogado, 2001.

. Dignidade da pessoa humana e direitos fundamentais na Constituição Federal de 1988. Porto Alegre: Livraria do Advogado, 2002.

SILVA, Fernanda Duarte Lopes Lucas da. Princípio Constitucional da Igualdade. Rio de Janeiro: Lumen Juris, 2003.

TEPEDINO, Gustavo. Temas de direito civil. 2. ed. rev. atual., Rio de Janeiro: Renovar, 2001. 